\title{
Flora da Bahia: Plumbaginaceae
}

\section{Evelyne Marques Marreira ${ }^{1 *}$, Paulo Ricardo Machado de Almeida ${ }^{1, a}$, Ana Maria Giulietti ${ }^{1,2, b}$ \& Reyjane Patricia de Oliveira ${ }^{1, c}$}

${ }^{1}$ Programa de Pós-graduação em Botânica, Departamento de Ciências Biológicas, Universidade Estadual de Feira de Santana, Feira de Santana, Bahia, Brasil.

${ }^{2}$ Instituto Tecnológico Vale de Desenvolvimento Sustentável, Belém, Pará, Brasil.

Resumo - É apresentada aqui a flora de Plumbaginaceae da Bahia, Brasil. Plumbago zeylanica foi a única espécie nativa (ou subespontânea) reconhecida no estado. São apresentadas descrições da família, do gênero e da espécie, além de ilustrações, mapa de distribuição e comentários gerais.

Palavras-chave adicionais: Brasil, florística, Plumbago, taxonomia.

\begin{abstract}
Flora of Bahia: Plumbaginaceae) - The flora of the Plumbaginaceae from Bahia, Brazil, is presented here. Plumbago zeylanica was the only native (or subspontaneous) species recognized in the state. Descriptions of the family, genus and species, illustrations, a distribution map and general notes are presented.
\end{abstract}

Additional key words: Brazil, floristics, Plumbago, taxonomy.

\section{PLUMBAGINACEAE}

Ervas anuais ou perenes, arbustos ou lianas. Folhas alternas, frequentemente formando rosetas basais, simples, inteiras; estípulas geralmente ausentes. Inflorescências em cimeiras, panículas ou racemos, bracteadas. Flores pentâmeras, frequentemente vistosas, bissexuadas, actinomorfas, diclamídeas; cálice parcialmente gamossépalo, frequentemente com tricomas glandulosos, às vezes petaloide; corola gamopétala, raramente dialipétala, prefloração convoluta; estames 5, opostos às pétalas, livres, raramente epipétalos, anteras bitecas, rimosas; ovário súpero, 5-carpelar, 1-locular, 1-ovulado, placentação basal, estiletes livres entre si ou apenas 1. Frutos aquênios secos, membranáceos, total ou parcialmente envolvidos pelo cálice persistente, ou cápsulas com deiscência circuncisa, podendo a parte deiscente se separar para o ápice em 5 valvas; semente 1, ereta, com ou sem endosperma.

Plumbaginaceae está inserida na ordem Caryophyllales, como grupo irmão de Polygonaceae (APG IV 2016). Trata-se de uma família monofilética, com 27 a 30 gêneros e 650 a 1.000 espécies, com distribuição quase cosmopolita. Inclui duas subfamílias: Plumbaginoideae e Staticoideae; no Brasil, estão representadas pelos gêneros Plumbago L. e Limonium Mill., respectivamente (Kubitzki 1993; Lledó et al. 2001; Every 2010; Ding et al. 2012; Souza \& Lorenzi 2012). Duas espécies são supostamente nativas do

\footnotetext{
*Autora para correspondência: evelyne.marques@hotmail.com;

a ma.pauloricardo@gmail.com; banagiulietti@hotmail.com;

crpatricia@uefs.br

Editor responsável: Alessandro Rapini

Submetido: 18 dez. 2017; aceito: 28 dez. 2017

Publicação eletrônica: 29 dez. 2017; versão final: 13 abr. 2018
}

Brasil: uma delas, Limonium brasiliense (Boiss.) Kuntze, é encontrada principalmente nas restingas do sul do país e a outra, amplamente distribuída no país, foi historicamente reconhecida como Plumbago scandens L. (BFG 2015), espécie neotropical, mas que vem sendo, mais recentemente, tratada como sinônimo de $P$. zeylanica $\mathrm{L}$.

\section{Plumbago L.}

Ervas perenes ou arbustos. Caule com ramos longos, delgados, flexuosos, glabros, estriados, ramos florais glandular-viscosos. Folhas ovais a oblongas, ápice e base atenuados, amplexicaules. Inflorescências em racemos terminais ou espigas, 1 bráctea e 2 bractéolas por flor. Flores vistosas, azuis, brancas ou vermelhas, curtamente pediceladas ou sésseis; cálice tubuloso, 5-costado, glanduloso e glutinoso externamente, lobos curtos, eretos; corola hipocrateriforme, lobos estendidos; estames livres ou adnatos à corola; gineceu 1, ovário ovoide, estilete único, ramos estigmáticos 5 , plumosos. Frutos cápsulas circuncisas na base, a parte deiscente se separando para o ápice em 5 valvas. Sementes com cotilédones planos e endosperma escasso.

Plumbago inclui 24 espécies, encontradas em regiões temperadas e tropicais (Short \& Wightman 2011). Ainda não existem estudos filogenéticos focando esse gênero e apenas algumas de suas espécies foram amostradas em análises para a família (Ding et al. 2012; Moharrek et al. 2014). Dentre as espécies cultivadas no Brasil, destaca-se a sul-africana $P$. auriculata Lam., conhecida popularmente como belaemília. Com belas flores azuis, é usada como cerca viva ou pendente em muros (Souza \& Lorenzi 2012). A única espécie supostamente nativa (ou subespontânea) no Brasil é $P$. zeylanica, que ocorre na Bahia. 
Plumbago zeylanica L., Sp. Pl. 1: 151. 1753.

Figuras 1-3.

Subarbustos ou arbustos escandentes a decumbentes, 0,4-1 $\mathrm{m}$ alt. Caule cilíndrico, glabro, com estrias verticais, marrom-claro. Folhas com pecíolo 0,4-1,2 mm compr., amplexicaule; lâmina 3$12 \times 1,1-4,5 \mathrm{~cm}$, oval a elíptica, ápice agudo, base decorrente a atenuada, membranácea a cartácea, margem inteira, faces adaxial e abaxial glabras. Inflorescências em racemos terminais, $7,5-28 \mathrm{~cm}$ compr.; pedúnculo 1-7 cm compr., brácteas elípticas, bractéolas ovais, glabras, verdes. Flores com pedicelo 1-2 mm compr.; cálice tubuloso, verde-claro, externamente glutinoso, $0,8-1,1 \mathrm{~cm}$ compr., lobos eretos; corola branca, glabra, tubo 1,3-2 cm compr., lobos obovados, mucronados, $0,4-0,7 \mathrm{~cm}$ compr.; estames livres, anteras 1,1-1,5 mm compr., rimosas, dorsifixas, azuis; ovário súpero, 5-carpelar, estilete ca. $1,5 \mathrm{~cm}$ compr., ramos estigmáticos 5 , ca. $0,5 \mathrm{~mm}$ compr. Frutos totalmente envolvidos pelo cálice, 0,5$0,8 \mathrm{~cm}$ compr. Sementes ovoides, marrons, $0,4-0,6 \mathrm{~cm}$ compr.

Distribuição pantropical (Pant et al. 2012). No Brasil, é referida (como Plumbago scandens) para todas as Regiões, do Amazonas ao Paraná, associada a bordas de florestas de restinga, caatinga ou mata atlântica (BFG 2015). B4, B8, C7, C8, C9, D5, D6, D7, D8, D10, E4, E5, E6, E7, E8, E9, F5, F6, F7, G3, G4, G6, G7, G8, H8, I8 e J8: amplamente distribuída em diversos tipos vegetacionais, principalmente em áreas de caatinga, restinga e floresta atlântica. Floresce e frutifica durante o ano todo.

Material selecionado - Alcobaça, $17^{\circ} 30^{\prime} \mathrm{S}, 39^{\circ} 13^{\prime} \mathrm{W}, 15$ jan. 1977 (fl.), R.M. Harley 17937 (CEPEC); Andaraí, 1254'46"S, 41 ${ }^{\circ} 19^{\prime} 06^{\prime \prime W}, 25$ fev. 2007 (bot., fl., fr.), R.M. Harley et al. 55614

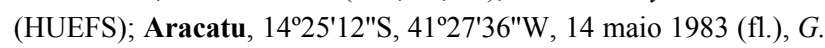
Hatschbach 46393 (CEPEC); Aramari, 1204'48"S, 39²9'24"W, 16 jul. 1981 (fl.), E.L.P.G. Oliveira 324 (HUEFS); Barra,14²14'54"S,

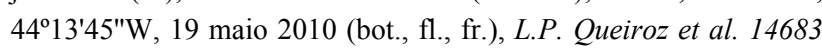
(HUEFS); Bom Jesus da Lapa, 13ำ15'32"S, 40²5'11"W, 15 maio 2001 (bot., fl.), F. França et al. 3514 (CEPEC, HUEFS); Brotas de Macaúbas, 1259'24"S, 42³7'12"W, 23 dez. 1995 (fl.), M.P. Silva 2 (ALCB); Camaçari, 12 $41^{\prime} \mathrm{S}, 38^{\circ} 19^{\prime} \mathrm{W}, 14$ set. 2002 (fl.), M.L. Guedes et al. 9575 (ALCB); Campo Alegre de Lourdes, 09²9'53"S, 4305'05"W, 14 jun. 2001 (fl., fr.), T.S. Nunes 396

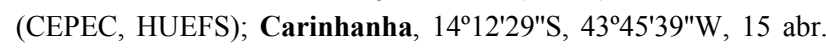
2001 (fl., fr.), J.G. Jardim 3539 (CEPEC); Castro Alves, $12^{\circ} 45^{\prime} \mathrm{S}$, $39^{\circ} 25^{\prime} \mathrm{W}, 2$ maio 1958 (fl., fr.), R.P. Lordêlo 5843 (ALCB); Cocos,

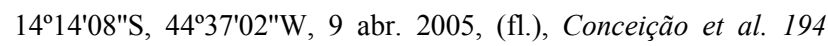
(HUEFS); Conceição de Feira, 12 $2^{\circ} 32^{\prime} 60^{\prime \prime} \mathrm{S}, 39^{\circ} 05^{\prime} 60^{\prime \prime} \mathrm{W}$, maio 1980, (fl.), Grupo Pedra do Cavalo 21 (HUEFS); Conceição do

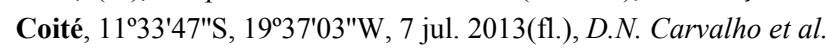

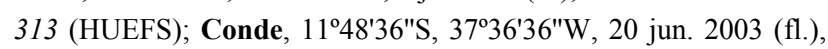
G. Hatschbach 75551 (CEPEC); Curaçá, 09 ${ }^{\circ} 19^{\prime} 53$ "S, 39³1'12"W, 13 mar. 2011 (fl. fr.), E. Melo et al. 9436 (HUEFS); Feira da Mata, 14¹4'54"S, 44¹3'45"W, 6 maio 2007 (bot., fl., fr.), M.L. Guedes et al. 13411 (ALCB, HUEFS); Feira de Santana, 12 ${ }^{\circ} 15^{\prime} 36^{\prime \prime}$, 38 57'36"W, 4 jun. 1994, (fl.), E. Melo et al. 1093 (HUEFS);

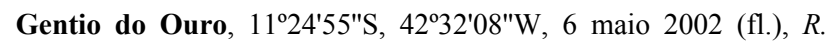

Tourinho et al. 13 (ALCB, HUEFS); Ibitiara, 12 $39^{\prime} 55^{\prime \prime S}$, $42^{\circ} 18^{\prime} 50^{\prime \prime} \mathrm{W}, 11$ out. 2007 (fl., fr.), A.A. Conceição et al. 2545 (HUEFS); Ipecaetá, 12²0'60"S, 39 $17^{\circ} 60^{\prime \prime} \mathrm{W}, 10$ out. 1999 (fl. fr.), D.J. Gomes et al. 30 (HUEFS); Ipiaú, 14²3'19"S, 3949'20"W, 2 maio 1969 (fl., fr.), J.A. Jesus 365 (CEPEC); Ipirá, 1209'S, 3943'48"W, 10 set. 1956 (fl.), E. Pereira 1994 (CEPEC); Itaberaba, $12^{\circ} 30^{\prime} \mathrm{S}, 40^{\circ} 04^{\prime} \mathrm{W}, 4$ jun. 2005 (bot., fl., fr.), E. Melo et al. 3885 (HUEFS); Itapebi, 155''ㅇ'S, 39³2'20"W, 14 ago. 1971 (fl., fr.), J.A. Jesus 365 (CEPEC); Itatim, $12^{\circ} 42^{\prime} \mathrm{S}, 39^{\circ} 46^{\prime} \mathrm{W}, 12 \mathrm{abr}$. 2000 (bot., fl., fr.), C. Correia et al. 6 (ALCB, HUEFS); Itiúba, $10^{\circ} 43^{\prime} \mathrm{S}, 39^{\circ} 50^{\prime} \mathrm{W}, 26$ maio 1983 (fl.), H.P. Bautista et al. 755 (ALCB); Ituaçu, $13^{\circ} 50^{\prime} \mathrm{S}, 41^{\circ} 18^{\prime} \mathrm{W}, 20$ jun. 1987 (fl.), L.P.

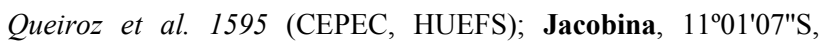
40³3'43"W, 6 jul. 1996 (fl.), H.P. Bautista et al. 3467 (CEPEC, HUEFS); Jaguarari, $10^{\circ} 11^{\prime} 41^{\prime \prime S}, 40^{\circ} 13^{\prime} 28^{\prime \prime} \mathrm{W}, 28$ jul. 2005 (bot., fl., fr.), D.S. Carneiro-Torres et al. 397 (HUEFS); Lafaiete Coutinho, 13³9'20"S, 40¹2'45"W, 6 maio 1979 (fl., fr.), S.A. Mori 11828 (CEPEC); Lajedinho, 12² $21^{\prime} \mathrm{S}, 40^{\circ} 54^{\prime} \mathrm{W}$, jun. 1968 (fl., fr.), A.L. Costa s.n. (ALCB 3230); Lençóis, 12³3'36"S, 41ํ2'48"W, 1 ago. 1999 (fl. fr.), R. Voeks et al. 592 (HUEFS); Livramento do

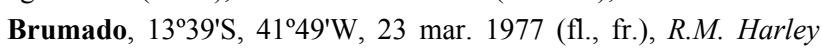
19887 (CEPEC); Manoel Vitorino, 1409'08"S, 40¹5'06"W, 16 maio 2005 (bot., fl., fr.), M.M. Silva-Castro et al. 551 (HUEFS); Maracás, $13^{\circ} 14^{\prime} 20^{\prime \prime S}, 40^{\circ} 34^{\prime} 15^{\prime \prime} \mathrm{W}, 3$ nov. 2011 (fl.), E. Melo et al. 10602 (HUEFS); Miguel Calmon, 1141'66"S, 40³4'52"W, 4 abr. 2001 (bot., fl.), T. Ribeiro et al. 142 (ALCB, HUEFS); Monte Santo, $10^{\circ} 25^{\prime} 59^{\prime \prime} \mathrm{S}, 39^{\circ} 19^{\prime} 12^{\prime \prime W}, 12$ jan. 2006 (fl., fr.), M.L. Guedes 12136 (ALCB); Morro do Chapéu, $11^{\circ} 15^{\prime} 28^{\prime \prime S}, 41^{\circ} 10^{\prime} 40^{\prime \prime} \mathrm{W}, 5$ maio 2007 (bot., fl., fr.), J.M. Gonçalves et al. 183 (HUEFS); Paramirim, $13^{\circ} 18^{\prime} 47^{\prime \prime S}, 42^{\circ} 15^{\prime} 50^{\prime \prime} \mathrm{W}, 29$ abr. 2007(fl., fr.), A.A. Conceição et al. 1979 (HUEFS); Porto Seguro, 16 ${ }^{\circ} 51^{\prime} \mathrm{S}, 39^{\circ} 08^{\prime} \mathrm{W}$, 12 set. 1998 (fl.), M.B. Thomas 524 (CEPEC); Retirolândia,

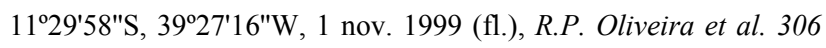
(HUEFS); Riachão do Jacuípe, $11^{\circ} 22^{\prime} \mathrm{S}, 39^{\circ} 49^{\prime} \mathrm{W}, 10$ jul. 1985 (fl.), L.R. Noblick 4061 (ALBC, CEPEC, HUEFS); Rio de Contas,

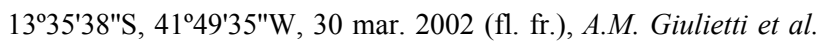
2072 (HUEFS); Salvador, 1258'12"S, 38³0'36"W, 5 set. 1996 (fl.), G.L. Campos et al. 17 (ALBC, CEPEC, HUEFS); Senhor do Bonfim, 10²3'19"S, 40¹3'24"W, 29 jul. 2005 (bot., fl., fr.), V.J. Santos et al. 469 (HUEFS); Tucano, 1054'31"S, 3859'06"W, 12 jul. 2004 (bot., fl.), D. Cardoso 160 (HUEFS); Ubaitaba, $14^{\circ} 18^{\prime} 45^{\prime \prime S}, 39^{\circ} 19^{\prime} 23^{\prime \prime W}, 24$ abr. 2001 (fl., fr.), R.S. Pinheiro 1239

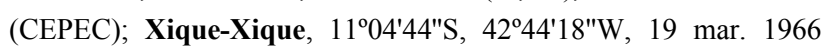
(fl.), A.A. Conceição et al. 2543 (HUEFS).

No Brasil, tem sido tratada como Plumbago scandens L. (Sp. Pl., ed. 2, 1: 215. 1762), espécie neotropical e a única do gênero supostamente nativa (e.g., Schmidt 1878; BFG 2015; Flora do Brasil 2020, em construção). No entanto, na monografia da espécie, Pant et al. (2012) consideraram P. zeylanica L. (Sp. Pl. 1: 151. 1753), até então reconhecida apenas para os continentes asiático e australiano, como tendo distribuição pantropical. Este nome mais antigo é adotado na Flora da América do Norte (Smith 2005) e nas listas florísticas da Bolívia (Paniagua Zambrana 2014), Colômbia (Bernal et al. 2015), Venezuela e Guianas (Funk et al. 2007), entre outras, que consideram $P$. scandens em sua sinonímia. Tal classificação é também adotada aqui, porém 


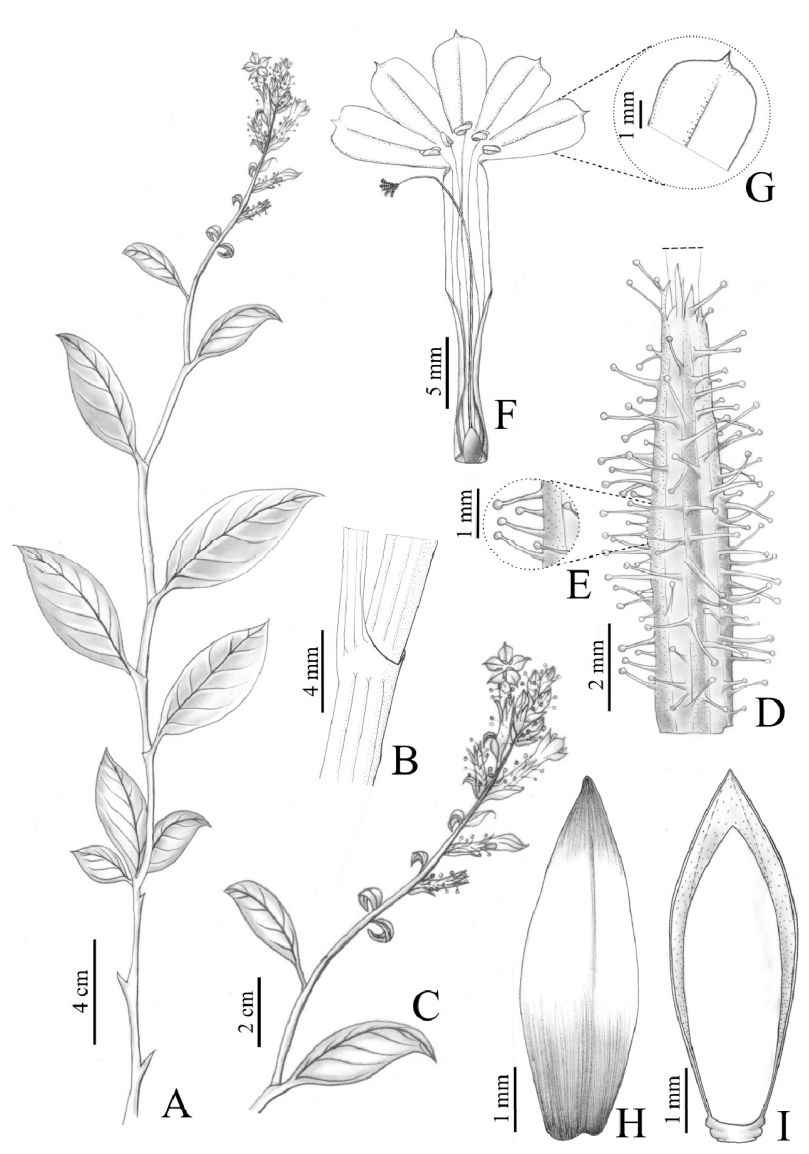

Figura 1. Plumbago zeylanica: A- ramo com inflorescência; B- detalhe do pecíolo invaginante; C- detalhe da inflorescência; D- cálice; E- detalhes das glândulas do cálice; F- flor aberta mostrando detalhes do ovário, estilete, estigma e estames; G- detalhe do ápice dos lobos das pétalas mucronados; H- fruto; I- secção do fruto mostrando a semente (A-C-Cardoso 160; D, ESilva 8; F, G- Conceição 1979; H- Santos 469; I-Mori 11828).

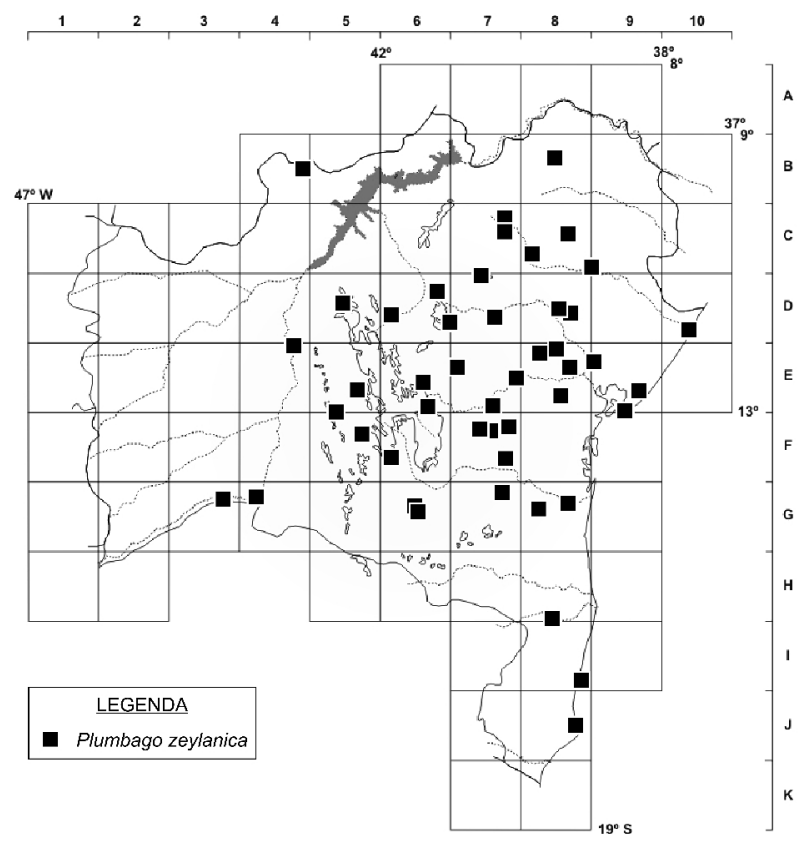

Figura 2. Mapa de distribuição de Plumbago zeylanica no estado da Bahia.
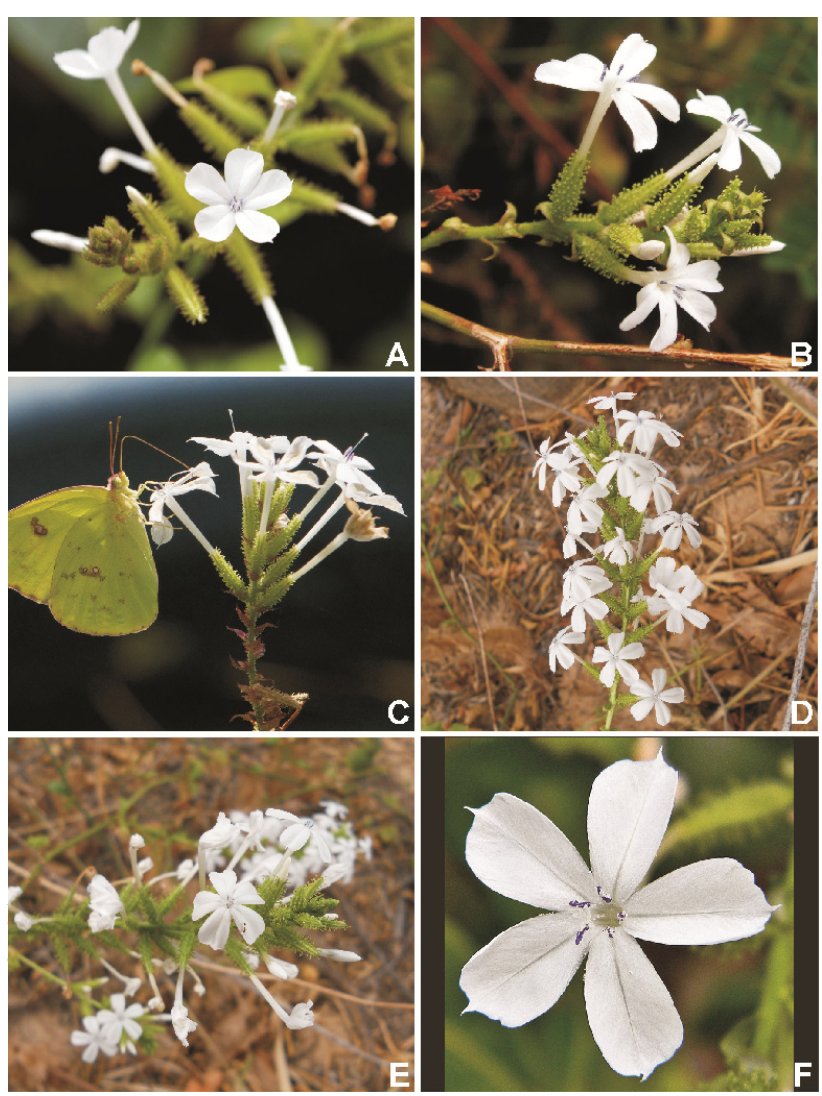

Figura 3. Plumbago zeylanica: A-E- inflorescência; F- flor (fotos: A- Laura Maretto; B- Sandy Overseas; C- Jim McCulloch; D, ELucas Marinho; F- Bob Peterson).

consideramos importante a realização de estudos comparativos ao longo de toda a distribuição da espécie para avaliar sua identidade.

Plumbago zeylanica se distingue das demais espécies do gênero, inclusive de $P$. auriculata, pela presença de cálice glanduloso e glutinoso externamente, corola branca e anteras azuis. É uma erva medicinal com grande produção de metabólitos secundários, com destaque para as naftoquinonas (plumbagina), produzidas especialmente nas raízes (Pant et al. 2012). No Brasil (como P. scandens), tem sido considerada tóxica, especialmente devido à presença de plumbagina, que também ocorre em $P$. auriculata (Paiva et al. 2002).

\section{AGRADECIMENTOS}

Os autores agradecem à Ellen Kallyne de Sousa Brandão, pela ilustração em nanquim; a Lucas Marinho, Laura Maretto, Jim McCulloch Sandy Overseas e Bob Peterson, pelas imagens; aos curadores dos herbários visitados, pela possibilidade de análise do material; à Fundação de Amparo à Pesquisa do Estado da Bahia (FAPESB) e ao Conselho Nacional de Desenvolvimento Científico e Tecnológico (CNPq), pelo apoio financeiro aos programas Flora da Bahia (processos APR 162/2007, 562278/2010-9 e 483909/2012-2) e PPBIO Semiárido. Os autores 
agradecem ainda ao CNPq, pelas bolsas concedidas à AMG (PQ Senior) e à RPO (PQ 1D), e à Capes, pela bolsa concedida à EMM.

\section{REFERÊNCIAS}

APG IV 2016. An update of the Angiosperm Phylogeny Group classification for the orders and families of flowering plants: APG IV. Botanical Journal of the Linnean Society 181: 1-20.

Bernal, R.; Gradstein, S.R. \& Celis, M. (eds). 2015. Catálogo de Plantas e Líquens de Colômbia. Instituto de Ciencias Naturales, Universidade Nacional de Colômbia, Bogotá.

BFG (The Brazil Flora Group) 2015. Growing knowledge: an overview of Seed Plant diversity in Brazil. Rodriguésia 66(4): $1085-1113$.

Ding, G.; Zhang, D.; Yu, Y.; Zhao, L. \& Zhang, B. 2012. Phylogenetic relationship among related genera of Plumbaginaceae and preliminary genetic diversity of Limonium sinense in China. Gene 506: 400-403.

Every, J.L.R. 2010. Plumbaginaceae. In: W. Milliken, B. Klitgård \& A. Baracat (eds), Neotropikey - Interactive key and information resources for flowering plants of the Neotropics. Disponível em: www.kew.org/neotropikey; acesso em: 25 out 2017.

Flora do Brasil 2020, em construção. Plumbaginaceae. Jardim Botânico do Rio de Janeiro. Disponível em: http://floradobrasil.jbrj.gov.br/reflora/floradobrasil/FB192; acesso em: 09 out. 2017.

Funk, V.; Hollowell, T.; Berry, P.; Kelloff, C. \& Alexander, S.N. 2007. Checklist of the plants of the Guiana Shield (Venezuela: Amazonas, Bolivar, Delta Amacuro; Guyana, Surinam, French Guiana. Contributions from the United States National Herbarium 55: 1-584.

Kubitzki, K. 1993. Plumbaginaceae. In: K. Kubitzki, J.G. Rohwer \& V. Brittich, (eds), The Families and Genera of Vascular Plants. Vol. 2. Springer-Verlag, Berlin, p. 523-530.
Lledó, M.D.; Karis, P.O.; Crespo, M.B.; Fay, M.F. \& Chase, M.W. 2001. Phylogenetic position and taxonomic status of the genus Aegialitis and subfamilies Staticoideae and Plumbaginoideae (Plumbaginaceae): evidence from plastid DNA sequences and morphology. Plant Systematics and Evolution 229: 107-124.

Moharrek, F.; Osaloo, S.K. \& Assadi, M. 2014. Molecular phylogeny of Plumbaginaceae with emphasis on Acantholimon Boiss. based on nuclear and plastid DNA sequences in Iran. Biochemical Systematics and Ecology 57: 117-127.

Paiva, S.R.; Fontoura, L.A. \& Figueiredo, M.R. 2002. Perfil cromatográfico de duas espécies de Plumbaginaceae: Plumbago scandens L. e Plumbago auriculata Lam. Química Nova 25(5): 717-721.

Paniagua Zambrana, N.Y. 2014. Plumbaginaceae. In: P.M. Jørgensen,, M. Nee \& S. Beck (eds), Catalogo de las Plantas Vasculares de Bolívia. Monograph in Systematic Botany from the Missouri Botany Garden 127(2): 1035.

Pant, M.; Lal, A.; Rana, S. \& Rani, A. 2012. Plumbago zeylanica L.: a mini review. International Journal of Pharmaceutical Applications 3(3): 399-405.

Schmidt, J.A. 1878. Plumbagineae. In: C.F.P. Martius \& A.G. Eichler (eds), Flora Brasiliensis. Vol. 6, part 4. Frid. Fleischer, Leipzig, p. 162-166.

Short, P.S. \& Wightman, G.M. 2011. Plumbaginaceae. In: P.S. Short \& I.D. Cowie (eds), Flora of the Darwin Region. Vol. 1. Northern Territory Herbarium, Department of Natural Resources, Environment, the Arts and Sport, Darwin, p. 1-4.

Smith, A.R. 2005. Plumbago. In: Flora of North America Editorial Committee (eds) 1993+, Flora of North America North of Mexico 20+ vols. Vol. 5. New York. Disponível em: http://www.efloras.org/florataxon.aspx?flora_id=1\&taxon_id=1 26108; acesso em: $10 \mathrm{dez} .2017$.

Souza, V.C. \& Lorenzi, H. 2012. Botânica Sistemática: guia ilustrado para identificação das famílias de fanerógamas nativas e exóticas do Brasil, baseado em APG III. Instituto Plantarum, Nova Odessa.

\section{LISTA DE EXSICATAS}

Anjos, B.A. 11; Araújo, J.S. 101; Arbo, M.M. 7301; Bautista, H.P. 755, 3467; Belém, R.P. 889; Campos, G.L. 17; Cardoso, D. 160; Carneiro-Torres, D.S. 397, 1391; Carvalho, A.M. 602, 3971; Carvalho, D.N. 226, 313; Carvalho-Sobrinho, J.G. 239; Conceição, A.A. 1979, 2543, 2545; Conceição, S.F. 194, 223, 313; Correia, C. 6, 80; Costa, A.L. 1092; França, F. 3514, 6111; Giulietti, A.M. 2072, 2736 ; Gomes, D.J. 30; Gonçalves, J.M. 183; Grupo Pedra do Cavalo 21; Guedes, M.L. 9575, 12136, 13411; Harley, R.M. 3118, 16189 , 17219 , 17937, 19887, 21386, 53702, 55614; Hatschbach, G. 46393, 75551; Jardim, J.G. 693, 3539; Jesus, J.A. 365; Lanna, J.P. 1366; Lordêlo, R.P. 5843; Machado, R.F. 437; Magalhães, C.M. 225; Melo, E. 1093, 1377, 1398, 1548, 3885, 8467, 8696, 9436, 10602, 11409; Miranda, A.M. 6720; Moraes, A.C. 85; Moraes, A.O. 37; Mori, S.A. 11828; Noblick, L.R. 1037, 3863, 4061; Nunes, T.S. 396; Oliveira, E.L.P.G. 324; Oliveira, R.C. 2308; Oliveira, R.P. 306; Pastore, J.F.B. 2208, 2211; Pereira, E. 1994; Pinheiro, R.S. 1239; Queiroz, L.P. 1595, 1683, 4854, 5708, 6245, 7372, 7830, 12266, 13269, 14683; Ribeiro, A. J. 68; Ribeiro, T. 132, 142; Rodarte, A.T. 115; Roque, N. 3959, 4516; Santos, T.S. 803, 1815; Santos, V.J. 469; Silva, L.A.M. 4, 2285; Silva, M.F.B.L. 8, 55; Silva, M.P. 2; Silva-Castro, M.M. 551; Souza, E.B. 1351; Thomas, M.B. 524; Tourinho, R. 13; Vieira, L.P. 40; Voeks, R. 165, 592. 